\title{
Circumstantial Evidence for Phytoalexin Involvement in the Resistance of Peanuts to Aspergillus flavus
}

\author{
By HILARY R. WOTTON AND RICHARD N. STRANGE* \\ Department of Botany and Microbiology, University College London, Gower Street, \\ London WCIE 6BT, UK
}

(Received 11 October 1984)

\begin{abstract}
Three stilbene phytoalexins, elicited by slicing and incubating imbibed peanut kernels under aerobic conditions, inhibited spore germination and hyphal extension of Aspergillus flavus with $E_{50}$ values in the range $4.9-12.8 \mu \mathrm{g} \mathrm{ml}^{-1}$. Phytoalexin yield was dependent on cultivar, conditions and duration of incubation after slicing, and crop history. The yield of phytoalexin from ten cultivars studied, after slicing and incubating at $25^{\circ} \mathrm{C}$ for $24 \mathrm{~h}$, ranged from 28 to $935 \mu \mathrm{g}$ per $\mathrm{g}$ fresh weight and was negatively correlated with dry kernel colonization by $A$. flavus $[r=$ -0.868 when plotted as In (phytoalexin concn) against ln (percentage peanut colonization)]. When the incubation period was extended to $96 \mathrm{~h}$ there was no such correlation. Reduced phytoalexin yields were obtained when sliced kernels of one cultivar studied were incubated in water or at $37^{\circ} \mathrm{C}$, and no phytoalexin was obtained when the slices were incubated under nitrogen gas or frozen before aerobic incubation. Drought stress during pod development in four cultivars studied reduced phytoalexin yields of sliced kernels incubated at $25^{\circ} \mathrm{C}$ for $24 \mathrm{~h}$ by 17 $65 \%$ compared with non-stressed controls.
\end{abstract}

\section{INTRODUCTION}

Strains of Aspergillus flavus Link and the closely related species $A$. parasiticus Speare produce a group of secondary metabolites termed aflatoxins. Most work has been done with aflatoxin $\mathbf{B}_{1}$, which is the most poisonous (Wogan \& Pong, 1970). This compound, in addition to its toxicity to a wide range of animals, is also teratogenic and carcinogenic (Heathcote \& Hibbert, 1978 $b$; Wogan, 1966). These studies suggest that aflatoxin contaminated food may be a health hazard to man. Indeed, a positive association between aflatoxin ingestion and liver cancer in man has been found in many population studies in tropical regions of Africa, India, South-East Asia and the Philippines (Heathcote \& Hibbert, 1978b). Aflatoxin contamination of food has also been associated with kwashiorkor (Hendrickse et al., 1982).

Aflatoxins can occur in many food materials but peanut meal from tropical countries is one of the commodities most frequently contaminated (Hiscocks, 1965). Originally it was thought that invasion of peanuts and aflatoxin prouction occurred mainly in storage, but it is now known that infection may occur before or during harvest (Ashworth \& Langley, 1964; Williams \& McDonald, 1983).

Kernels of different cultivars of peanuts vary widely in their susceptibility to invasion by $A$. flavus when inoculated with a spore suspension, and this has been correlated with their susceptibility to A. flavus invasion in the field (Zambettakis, 1983). Variation in susceptibility to A. flavus invasion is also influenced by both pre- and post-harvest environmental factors (Mixon, 1981). These include the type of plant residue in the soil (Griffin \& Garren, 1976), the

Ahbreriation: $\mathrm{ED}_{50}$, effective dose $(50 \%)$. 


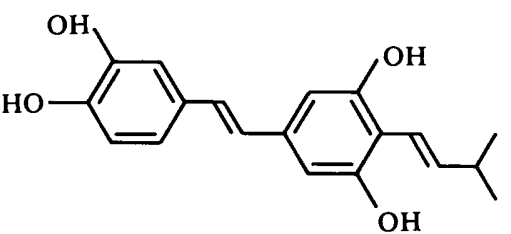

Arachidin I

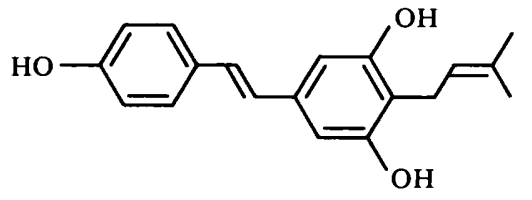

Arachidin II

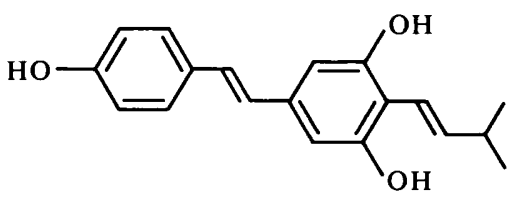

Arachidin III

Fig. 1. Chemical structures of three peanut kernel phytoalexins.

other mycoflora present (Joffe, 1969), the crop rotation practices (Pettit \& Taber, 1968), the age of kernels and the condition of the plants (McDonald \& Harkness, 1967). Invasion of the kernels is more rapid if the pods are damaged, for example by insects (Minton \& Jackson, 1967), by pod rotting fungi (Ashworth \& Langley, 1964), or by machinery during harvest (Dickens \& Khalsa, 1967). Severe drought stress during the last 4-6 weeks of the growing season increases the incidence of invasion of peanut kernels by A. flavus (Pettit et al., 1971) as does storage at high temperatures and relative humidities (Heathcote \& Hibbert, 1978a).

The nature of the greater resistance to $A$. flavus of some peanut genotypes compared with others is unknown, but has been associated with certain characteristics of the testa. These include wax accumulation on the surface (Zambettakis \& Bockelee-Morvan, 1976), pigmentation (Mixon 1981), thinness and tightness of fit (Glueck et al., 1977; Waliyar \& Abadie, 1978), low permeability to aqueous stains (La Prade \& Bartz, 1972) and low concentrations of certain amino acids (Amaya et al., 1980).

Recently, three stilbene phytoalexins were isolated in this laboratory from peanut kernels exposed to their native microflora; two of the compounds were novel and one had been previously described (Aguamah et al., 1981). These compounds have been assigned the trivial names arachidin I, II and III (Fig. 1). The relationship between the accumulation of these compounds in response to wounding and the resistance to colonization by $A$. flavus is the subject of this paper.

\section{METHODS}

Peanut kernels. Kernels of peanut (Arachis hypogaea) in their pods were kindly supplied by Dr R. C. N. Rao and Dr J. H. Williams of the International Crops Research Institute for the Semi-Arid Tropics (ICRISAT), Pantancheru PO, Andhra Pradesh 502324, India. Four cultivars were grown under drought stress conditions and were compared with the same cultivars grown under non-stress conditions. Details of the irrigation regime are given in Table 1. Seed was treated with fungicides Captan and Thiram ( $3 \mathrm{~g}$ per $\mathrm{kg}$ seed) and sown at ICRISAT on 27 November 1982 in $12 \mathrm{~m}$ rows. The inter-row spacing was $30 \mathrm{~cm}$ and the spacing between plants in the rows $10 \mathrm{~cm}$. The crop was protected against pests and diseases until maturity.

A. flatus. An isolate of the fungus IMI no. 91019 biii was obtained from the Tropical Development Research Institute, 56 Gray's Inn Road, London, UK. It was grown on malt/peptone agar in the dark at $25^{\circ} \mathrm{C}$.

Phytoalexins. Peanut kernels were shelled, sorted into $10 \mathrm{~g}$ batches and surface sterilized by immersion in $\mathrm{H}_{2} \mathrm{O}_{2}$ $(30 \%, \mathrm{w} / \mathrm{v})$ for $30 \mathrm{~min}$. They were rinsed three times in sterile distilled water and allowed to imbibe sterile distilled water for $16 \mathrm{~h}$ at $25^{\circ} \mathrm{C}$. Samples were cut into transverse sections $2 \mathrm{~mm}$ thick with a sterile multi-blade knife before incubating in Petri dishes $\left(90 \mathrm{~mm}\right.$ diam.) at $25^{\circ} \mathrm{C}$ or (for one experiment) $37^{\circ} \mathrm{C}$ in the dark. Routinely, the Petri dishes were opened under sterile conditions every $24 \mathrm{~h}$ and the contents stirred to ensure adequate aeration. In some experiments the batches of sliced kernels were incubated with $0,1,2,3,4$ or $5 \mathrm{ml}$ sterile distilled water while in others the samples were gassed with $\mathrm{N}_{2}$. 
Table 1. Irrigation regime in drought stressed and non-stressed plots

Four cultivars of peanut, NcAc 17094, EC 76446, Robut 33 and $\mathrm{TMV}_{2}$, were planted on 27 November 1982 at ICRISAT, Andhra Pradesh, India.

\begin{tabular}{|c|c|c|}
\hline \multirow{2}{*}{$\begin{array}{c}\text { Days after } \\
\text { planting }\end{array}$} & \multicolumn{2}{|c|}{ Water applied to plots (mm) } \\
\hline & Dry treatment & Wet treatment \\
\hline 3 & Field capacity & Field capacity \\
\hline 11 & 10 & - \\
\hline 16 & 10 & 10 \\
\hline 27 & - & 10 \\
\hline 47 & - & 10 \\
\hline 60 & - & 10 \\
\hline 69 & - & 10 \\
\hline 72$\}$ & 70 & - \\
\hline 81 & - & Field capacity \\
\hline 89 & - & Field capacity \\
\hline 97 & - & Field capacity \\
\hline 105 & - & Field capacity \\
\hline 106 & 60 & - \\
\hline 112 & $60+11 \cdot 5^{*}$ & Field capacity $+11 \cdot 5^{*}$ \\
\hline 119 & - & Field capacity \\
\hline 126 & - & Field capacity \\
\hline 133 & 50 & - \\
\hline 134 & - & Field capacity \\
\hline
\end{tabular}

The phytoalexins were extracted and quantified by HPLC, essentially as previously described (Aguamah et al., 1981). Larger samples of the phytoalexins, for antifungal assays, were also prepared by HPLC (Aguamah et al., 1981).

Antifungal assays. Spores of A. flavus from malt/peptone agar Petri plates (1-2 weeks old) were harvested in sterile distilled water $(10 \mathrm{ml})$ by agitation with a sterile glass rod. The resulting suspension was filtered through four thicknesses of sterile muslin and centrifuged for $15 \mathrm{~min}$ at $700 \mathrm{~g}$. The pelleted spores were resuspended in sterile distilled water and washed twice more in the centrifuge. They were finally suspended in sterile distilled water $\left(10^{5}\right.$ spores $\left.\mathrm{ml}^{-1}\right)$.

The three peanut phytoalexins were dissolved in $95 \%(\mathrm{v} / \mathrm{v})$ ethanol, and duplicates of a dilution series were distributed to the wells of a microtest plate (Flow Laboratories). After removal of the alcohol by evaporation in a current of air, Vogel's medium (Vogel, 1956) containing $2 \%(\mathrm{w} / \mathrm{v})$ sucrose and $1.5 \%(\mathrm{w} / \mathrm{v})$ agar $(0 \cdot 1 \mathrm{ml})$ was added to each well. The final concentrations of the phytoalexins were $100 \cdot 00,36 \cdot 10,10.00,3.61,1.00$ and $0.00 \mu \mathrm{g} \mathrm{ml}^{-1}$.

Spore suspension $(4 \mu \mathrm{l})$ was placed on the agar in each well and the plate incubated in the dark at $25^{\circ} \mathrm{C}$. After incubation for $12 \mathrm{~h}$ a drop of cotton blue/lactophenol was added to prevent any further growth and to stain the fungus. Germination was assessed for 100 spores from each well, those spores with the germ tube longer than the diameter of the spore being scored as germinated. The percentage inhibition caused by the phytoalexins was calculated using the formula $[(C-T) / C] \times 100$, where $C=$ mean percentage germination in controls, and $T=$ mean percentage germination in tests.

The effect of the phytoalexins on germ tube extension was also assessed. Cellophane discs ( $5 \mathrm{~mm}$ diam.) were boiled for $2 \mathrm{~min}$ in water to remove plasticizers, dried, and sterilized at $121^{\circ} \mathrm{C}$ in the autoclave for $15 \mathrm{~min}$ before being placed on Vogel's medium, containing $2 \%$ sucrose and $1.5 \%$ agar $(20 \mathrm{ml})$, in a Petri dish $(9 \mathrm{~cm}$ diam.). Spore suspension $(2 \mu \mathrm{l})$ was placed on each disc and incubated for $15 \mathrm{~h}$. A drop of cotton blue/lactophenol was placed on a sample of the discs and the length of 25 germ tubes per disc measured under a microscope using the $\times 40$ objective and a graticule eye piece. A microtest plate was set up as described above for the spore germination tests $(0 \cdot 1 \mathrm{ml}$ agar per well together with a dilution series of the phytoalexins). One cellophane disc with sporelings was placed on the agar in each well, and the microtest plate incubated for a further $15 \mathrm{~h}$. A drop of cotton blue/lactophenol was placed in each well, and 25 germ tubes from each well were measured. The average length was calculated and converted into percentage inhibition using the formula $\left[\left(L_{\mathrm{C}}-L_{\mathrm{F}}\right) /\left(L_{\mathrm{C}}-L_{\mathrm{O}}\right)\right] \times 100$, where $L_{\mathrm{C}}=$ the final length of the germ tubes incubated without phytoalexins, $L_{O}=$ the length of the germ tubes at the time of phytoalexin addition, and $L_{\mathrm{F}}=$ the final length of the germ tubes incubated with phytoalexins.

$E D_{s 0}$ values were calculated from the regression of percentage inhibition on $\log _{10}$ (concentration of phytoalexins). 


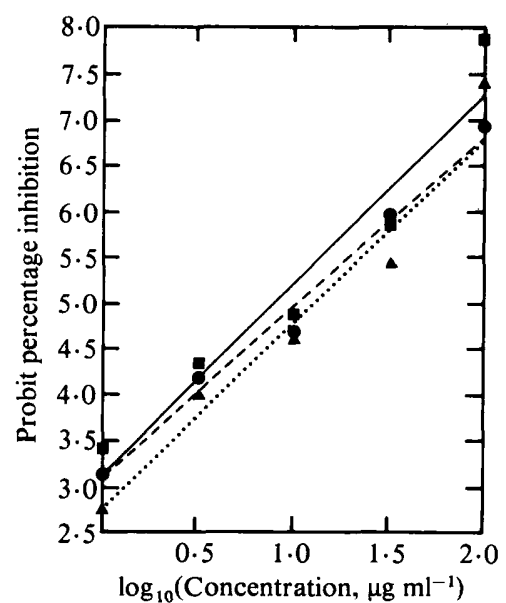

Fig. 2

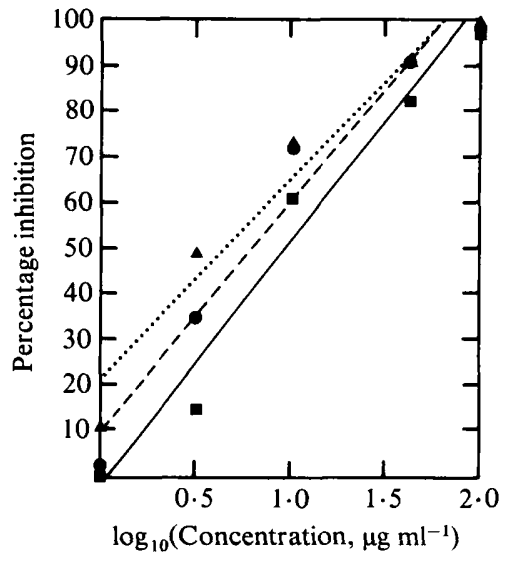

Fig. 3

Fig. 2. Relationship between probit percentage inhibition of spore germination and the logarithm of phytoalexin concentration. (Combined results from three experiments, maximum SD $<1.0$ probit unit.) $\Delta \cdots \cdots \mathbf{\Delta}$, Arachidin I; compounds were $12.8,12.7$ and $8.9 \mu \mathrm{g} \mathrm{ml}^{-1}$ respectively.

Fig. 3. Relationship between percentage inhibition of hyphal extension and the logarithm of phytoalexin concentration. (Combined results from three experiments, maximum SD $<12 \%$.) $\Delta \cdots \cdots \mathbf{\Delta}$, Arachidin I; - arachidin II; $\square$, arachidin III. The ED $_{50}$ values for these compounds were $4 \cdot 9,6 \cdot 8$ and $9.9 \mu \mathrm{g} \mathrm{ml}^{-1}$ respectively.

\section{RESULTS}

Inhibition of $A$. flavus by the peanut phytoalexins

Spore germination and hyphal extension of $A$. flavus were inhibited by all three peanut phytoalexins, as compared with controls incubated without the compounds. Both probit percentage inhibition of germination and percentage inhibition of hyphal extension were proportional to the logarithm of phytoalexin concentration in the range $1-100 \mu \mathrm{g} \mathrm{ml}^{-1}$. The $\mathrm{ED}_{50}$ values for spore germination were $12.8,12.7$ and $8.9 \mu \mathrm{g} \mathrm{ml}^{-1}$ for arachidin I, II and III respectively (Fig. 2). The $\mathrm{ED}_{50}$ values for hyphal extension were $4.9,6.8$ and $9 \cdot 7 \mu \mathrm{g} \mathrm{ml}^{-1}$ for arachidin I, II and III respectively (Fig. 3).

\section{Phytoalexin accumulation in peanut kernels after wounding}

Phytoalexins accumulated within $24 \mathrm{~h}$ of wounding peanut kernels and reached maximum concentrations in 96-120 h, after which they began to decline (Fig. 4). The three cultivars chosen differed in their speed of response. Cultivar $\mathrm{TMV}_{2}$ produced the least phytoalexin at $24 \mathrm{~h}$

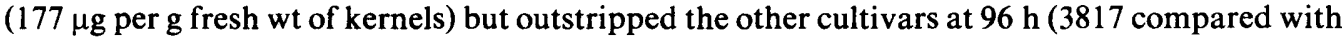
1028 and $1647 \mu \mathrm{g}$ per $\mathrm{g}$ fresh wt). When phytoalexin concentration in ten cultivars was measured $24 \mathrm{~h}$ after wounding and compared with their reported susceptibility to 'dry seed' colonization by $A$. flavus (Mehan et al., 1981), a negative correlation was found between the two factors, particularly when the data were expressed as natural logarithms $(r=-0.868)$ (Fig. 5). No such relationship held between phytoalexin concentrations accumulated $96 \mathrm{~h}$ after wounding and dry seed susceptibility to colonization (Table 2).

Incubation of sliced kernels of cultivar $\mathrm{TMV}_{2}$ at $37^{\circ} \mathrm{C}$ rather than $25^{\circ} \mathrm{C}$ slowed phytoalexin accumulation (Fig. 6). The addition of varying amounts of sterile distilled water to sliced samples of the cultivar in Petri dishes also decreased phytoalexin accumulation, suggesting that aerobic conditions might be important (Fig. 7). Gassing samples of $T M V_{2}$ with $N_{2}$ virtually abolished phytoalexin accumulation (after an incubation period of $96 \mathrm{~h}$ the mean phytoalexin 


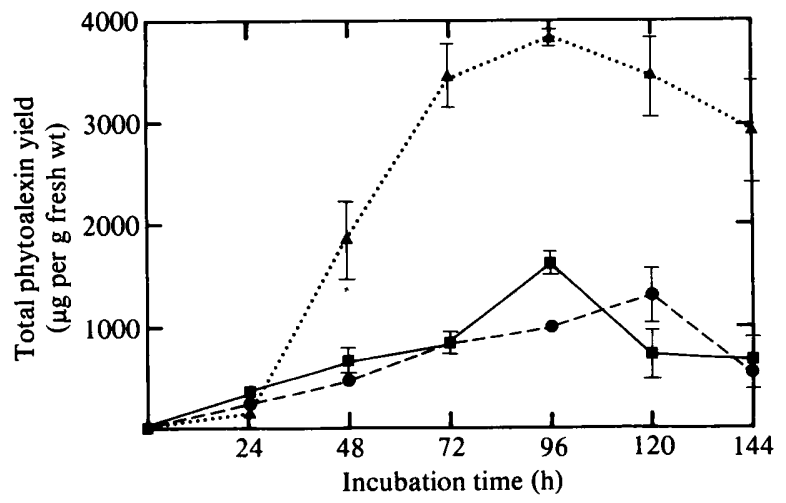

Fig. 4

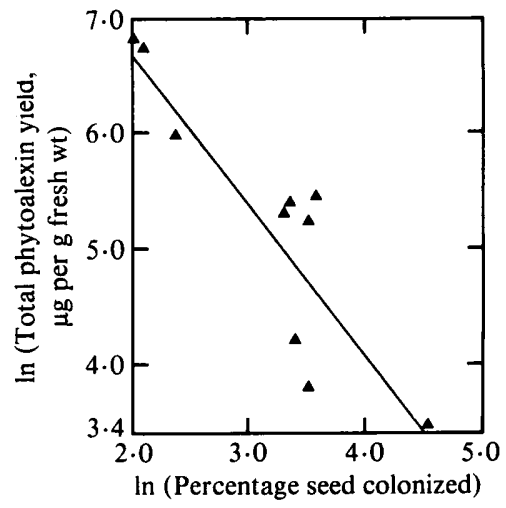

Fig. 5

Fig. 4. Phytoalexin accumulation in relation to the incubation time after wounding by slicing in three cultivars of peanut: $\operatorname{TMV}_{2}(\boldsymbol{\Delta} \cdots \cdots)$, Tamnut $74\left(\mathbf{O}_{---}\right)$and Florunner $(\square-\square)$. The bars represent \pm 1 SD for three replicates.

Fig. 5. Relationship between the natural logarithms of phytoalexin yield $24 \mathrm{~h}$ after wounding by slicing and percentage colonized kernels when inoculated with a spore suspension of $A$. flavus $(r=-0 \cdot 868)$ for ten cultivars of peanut (see Table 2). The data on percentage colonization are from Mehan et al. (1981).

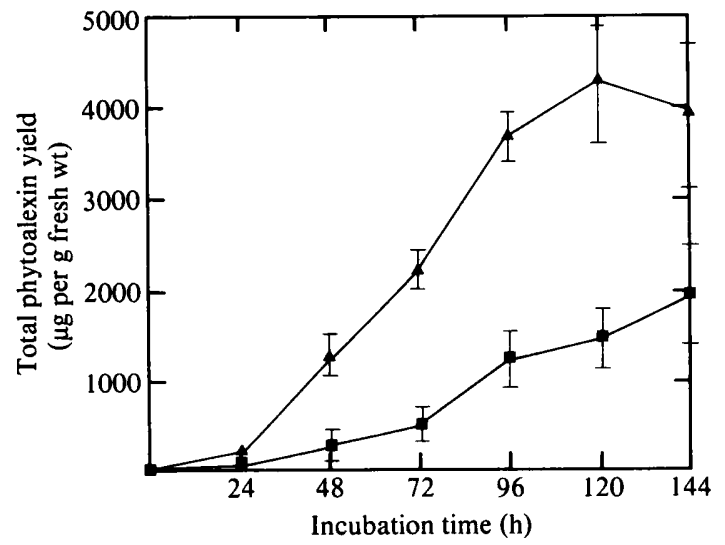

Fig. 6

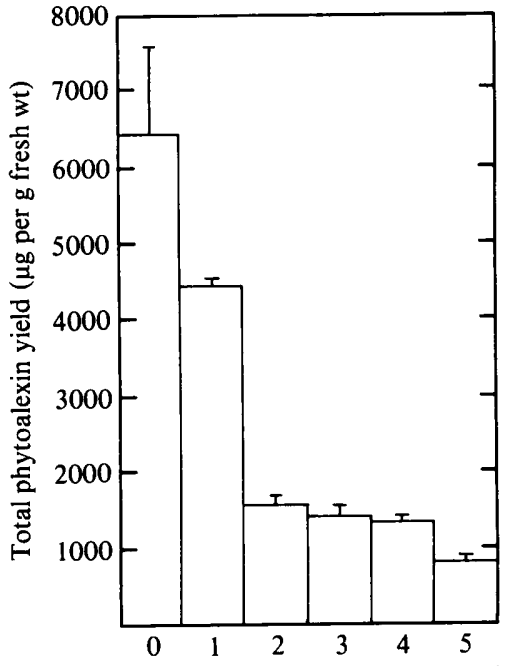

Vol. of water ( $\mathrm{ml}$ per $10 \mathrm{~g}$ sample)

Fig. 7

Fig. 6. Effect of incubation, after wounding by slicing, at two different temperatures, $25^{\circ} \mathrm{C}(\mathbf{A})$ and $37^{\circ} \mathrm{C}(\square)$, on phytoalexin yield in cultivar $\mathrm{TMV}_{2}$. The bars represent \pm 1 SD for three replicates.

Fig. 7. Effect of the addition of water to sliced kernels of cultivar $\mathrm{TMV}_{2}$ on phytoalexin yield after incubation for $96 \mathrm{~h}$. The bars represent \pm 1 SD for three replicates.

level, $\pm \mathrm{SD}$, was $103 \pm 50 \mu \mathrm{g}$ per $\mathrm{g}$ fresh wt compared with $4743 \pm 1090 \mu \mathrm{g}$ per $\mathrm{g}$ fresh wt for controls). Killing the samples of $\mathrm{TMV}_{2}$ by alternate freezing and thawing before incubation prevented any phytoalexin accumulation.

Kernels from drought stressed plants of four cultivars studied accumulated less phytoalexin by $17-65 \%$ than kernels from non-stressed plants (Fig. 8). 


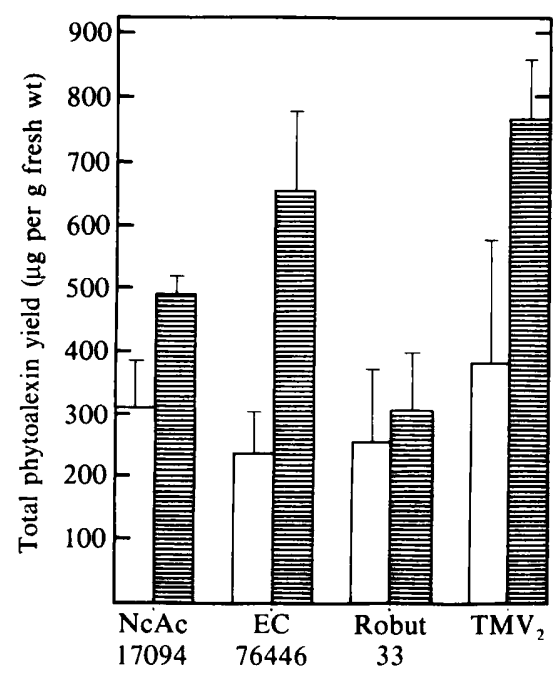

Fig. 8. Effect of drought stress on the capability of kernels to synthesize phytoalexins in four cultivars of peanut. Unhatched, dry treatment; hatched, wet treatment. Samples were incubated for $24 \mathrm{~h}$ after wounding by slicing. The bars represent \pm 1 SD for four replicates.

Table 2. Phytoalexin accumulation in peanut kernels $96 \mathrm{~h}$ after wounding by slicing

$\begin{array}{lc}\begin{array}{l}\text { Cultivar } \\ \text { (ICG no.) }\end{array} & \begin{array}{c}\text { Percentage of seeds } \\ \text { colonized when inoculated } \\ \text { with } A . \text { flavus* }\end{array} \\ 4749 & 7 \cdot 2 \\ 4750 & 8 \cdot 0 \\ 1326 & 10 \cdot 3 \\ 3836 & 27 \cdot 3 \\ \text { TMV } & 28 \cdot 4 \\ 4747 & 29 \cdot 7 \\ \text { Florunner } & 32 \cdot 8 \\ 801 & 32 \cdot 8 \\ 2716 & 33 \cdot 7 \\ 7867 & 94 \cdot 1 \\ & \text { * Data from Mehan et al. (1981). } \\ & \dagger \text { Means of three replicates, } \pm \text { SD. }\end{array}$

Total phytoalexin $\dagger$ $\left[\mu \mathrm{g}(\mathrm{g} \text { fresh wt })^{-1}\right]$

$$
\begin{aligned}
& 2981 \pm 431 \\
& 2421 \pm 376 \\
& 1940 \pm 348 \\
& 1195 \pm 55 \\
& 2325 \pm 269 \\
& 1109 \pm 203 \\
& 1059 \pm 56 \\
& 1921 \pm 474 \\
& 1020 \pm 32 \\
& 2343 \pm 62
\end{aligned}
$$

+ Means of three replicates, \pm SD

\section{DISCUSSION}

All three peanut phytoalexins inhibited both germination and hyphal extension of $A$. flavus in the $\mu \mathrm{g} \mathrm{ml}^{-1}$ range. Since peanut kernels are capable of synthesizing these compounds in the low $\mathrm{mg} \mathrm{g}^{-1}$ range (Aguamah et al., 1981), an investigation was begun into why $A$. flavus colonizes peanut kernels. There were differences between various cultivars in the initial rate of accumulation of phytoalexins in response to slicing and these differences correlated with their dry seed resistance to colonization by $\boldsymbol{A}$. flavus. It seems possible, therefore, that resistance to $\boldsymbol{A}$. flavus is related to the time of phytoalexin synthesis, and not to the final amounts that accumulate after prolonged incubation. This is in line with several reports documenting the role of phytoalexins in resistance. For example, Rossall \& Mansfield (1978) demonstrated, in experiments on the infection of Vicia faba leaves by Botrytis spp., that phytoalexin accumulation occurred at the right time to explain the inhibition of fungal growth during resistant reactions. Also Bailey et al. (1980) showed that in the invasion of Phaseolus vulgaris by Colletotrichum lindemuthianum, inhibition of hyphal growth occurred shortly after phytoalexins began to accumulate. Yoshikawa 
et al. (1978) have demonstrated that, in the challenge of soybean by Phytophthora megasperma var. sojae, glyceollin accumulated at a greater rate in resistant rather than in susceptible tissue.

In this study, conditions which promoted the invasion of peanuts by $A$. flavus also inhibited phytoalexin production. Thus kernels from drought stressed plants, which are more susceptible to $A$. flavus than kernels from non-drought stressed plants (Wogan \& Pong, 1970), produced less phytoalexin in response to wounding by slicing. Also, sliced kernels incubated at $37^{\circ} \mathrm{C}$ produced less phytoalexin than sliced kernels incubated at $25^{\circ} \mathrm{C}$. This latter finding may be of particular significance in the context of the work of Sanders et al. (1981) and Hill et al. (1983), who found that peanuts were more susceptible to $A$. flavus in soils at high rather than low temperatures. They also suggested that under conditions of drought stress the kernels were more susceptible to $A$. flavus invasion because the leaf canopy was reduced and, therefore, the temperature of the soil below the plants was higher.

Our results indicate that resistance of peanut kernels to invasion by $A$. flavus is correlated with their capacity to synthesize phytoalexins as an early response to wounding. Work is now in progress to determine whether the two phenomena are connected in a cause and effect relationship.

We are grateful for the receipt of a grant by one of us (H. R. W.) from the Tropical Development and Research Institute.

\section{REFERENCES}

Aguamah, G. E., Lancake, P., Leworthy, D. P., Page, J. A., Pryce, R. J. \& Strange, R. N. (1981). Two novel stilbene phytoalexins from Arachis hypogaea. Phytochemistry 20, 1381-1383.

Amaya, F. J., Young, C. T., Norden, A. J. \& Mixon, A. C. (1980). Chemical screening for Aspergillus flarus resistance in peanuts. Oléagineux 35, 255-259.

Ashworth, L. J. \& Langley, B. C. (1964). The relationship of pod damage to kernel damage by molds in Spanish peanuts. Plant Disease Reporter 48, 875-878.

Bailey, J. A., Rowell, P. M. \& Arnold, G. M. (1980). The temporal relationship between infected cell death, phytoalexin accumulation and inhibition of hyphal development during the resistance of Phaseolus vulgaris to Colletotrichum lindemuthianum. Physiological Plant Pathology 17, 329-339.

Dickens, J. W. \& Khalsa, J. S. (1967). Windrow orientation and harvesting damage to peanuts Oléagineux 22, 741-746.

Glueck, J. A., Clark, L. E. \& Smith, O. D. (1977). Testa comparisons of four peanut cultivars. Crop Science 17, 777-782.

Griffin, G. J. \& Garren, K. H. (1976). Colonisation of rye green manure and peanut fruit debris by Aspergillus flatus and Aspergillus niger group in field soils. Applied and Enrironmental Microbiology 32, 28 32.

Heathcote, J. G. \& Hibbert, J. R. (1978a). Production of aflatoxins. In Developments in Food Science. 1 Aflatoxins: Chemical and Biological Aspects, pp. 1629. Amsterdam: Elsevier Scientific Publishing Co.

Heathcote, J. G. \& Hibbert, J. R. (1978b). Pathological effects. In Derelopments in Food Science. 1. Aflatoxins: Chemical and Biological Aspects, pp. 83111. Amsterdam: Elsevier Scientific Publishing Co.

Hendrickse, R. G., Coulter, J. B. S., Lamplugh, S. M., MacFarlane, S. B. J., Williams, T. E., OMer, M. I. A. \& Suliman, G. I. (1982). Aflatoxins and kwashiorkor - a study in Sudanese children. British Medical Journal 285, 843-846.

Hill, R. A., Blankenship, P. D., Cole, R. J. \& SANDERS, T. H. (1983). Effects of soil moisture and temperature on pre-harvest invasion of peanuts by the Aspergillus flarus group and subsequent aflatoxin development. Applied and Environmental Microbi$o \log y$ 45, 628-633.

Hiscocks, E. S. (1965). The importance of molds in the deterioration of tropical foods and feedstuffs. In Mycotoxins in Foodstuffs, pp. 15-26. Edited by G. N. Wogan. Cambridge Mass.: M.I.T. Press.

JofFe, A. Z. (1969). Relationships between Aspergillus flarus and Aspergillus niger and some other fungi in the mycofiora of groundnut kernels. Plant and Soil 31, 57-64.

La Prade, J. C. \& Bartz, J. A. (1972). Mechanical resistance of selected genotypes of dried peanuts to colonisation by strains of aflatoxin producing Aspergillus flarus species. Phytopathology 62, 711.

MCDonald, D. \& HARKNESS, C. (1967). Aflatoxin in the groundnut crop at harvest in Northern Nigeria. Tropical Science 9, 148-161.

Mehan, V. K., MCDonald, D., Nigam, S. N. \& LaLitha, B. (1981). Groundnut cultivars with seed resistant to invasion by Aspergillus farus. Oléagineux 36, 501-505.

Minton, N. A. \& JACKsON, C. R. (1967). Invasion of peanut pods by Aspergillus flarus and other fungi in the presence of root-knot nematodes. Oléagineux 22 , 543-546.

MIXON, A. C. (1981). Reducing aflatoxin contamination in peanut genotypes by selection and breeding. Journal of the American Oil Chemists Society 58, 961966.

Pettit, R. E. \& TAber, R. A. (1968). Factors influencing aflatoxin accumulation in peanut and associated mycoflora. Applied Microbiology 16, 1230 1237. 
Pettit, R. E., Taber, R. A., Schroeder, H. W. \& HARRISON, A. L. (1971). Influence of fungicides and irrigation practice on aflatoxin in peanuts before digging. Applied Microbiology 22, 629-634.

Rossall, S. \& Mansfield, J. W. (1978). The activity of wyerone acid against Botrytis. Annals of Applied Biology 89, 359-362.

Sanders, T. H., Hill, R. A., Cole, R. J. \& Blankenship, P. D. (1981). Effect of drought on occurrence of Aspergillus flatus in maturing peanuts. Journal of the American Oil Chemists Society 58, 966970.

VoGEL, H. J. (1956). A convenient growth medium for Neurospora (medium N). Microbial Genetics Bulletin 13, 42-43.

WALIYAR, P. F. \& ABADIE, M. (1978). Ultrastructure de tégument séminal de quelques variétés d'arachide. Annales des sciences naturelles (Botanique) 19, 267282.

WILliams, R. J. \& MCDonald, D. (1983). Grain molds in the tropics; problems and importance. Annual Retiew of Phytopathology 21, 153-178.
WogaN, G. N. (1966). Chemical nature and biological effects of the aflatoxins. Bacteriological Reviews 30, 460-468.

Wogan, G. N. \& Pong, R. S. (1970). Aflatoxins. Annals of the New York Academy of Sciences 174, 623-635.

Yoshikawa, M., Yamachui, K. \& Masago, H. (1978). Glyceollin: its role in restricting fungal growth in resistant soybean hypocotyls infected with $P h y$ tophthora megasperma var sojae. Physiological Plant Pathology 12, 73-82.

ZambetTAKIS, C. (1983). Results of research on selected groundnut hybrids to limit Aspergillus flavus infection. Comptes rendus des séances de l'Académie d'agriculture de France 69, 44-50.

ZambetTakis, C. \& BockeleE-Morvan, A. (1976). Research on the structure of the seed tegument of groundnut and its effect on the penetration of Aspergillus flavus. Oléagineux 31, 219-228. 